some beautiful results, including the formation of fixed straight and curved coloured bands, arranged in symmetrical figures, and of pairs of colour-vortices rotating in opposite directions.

Unless these results prove to have been already described, I shall shortly publish an account of my experiments.

Trinity College, Cambridge, November I 2 Senley Taylor

\section{Expected High Tides}

IN your "Notes" last week you say that you cannot understand why the burden of such predictions should fall solely upon Capt. Saxby. This is what many of the public also do not understand. Why does not, say, the Meteorological Office take the matter in hand, and not leave it to some private individual ? There can be no doubt the forewarnings are often of the greatest service and have saved the public tens of thousands of pounds and prevented a great deal of misery. What I think Capt. Saxby is to be blamed for is the desire--it may be only apparent-to make a mystery of his predictions with the general public; and what gives weight to this is the fact that the Astronomer-Royal and the heads of the Meteorological Office and Society do not offer the public any aid in wbat is a purely scientific and eminently practical subject, in which Londoners are more interested than in the transit of Venus, and quite as much as in the storm-warnings for the Channel.

When in March, 1874, Capt. Saxby came forward and in an oracular way predicted a great tide on the 20 th, he gave no reasons. This many felt was unsatisfactory. Knowing that it must result from the action of natural laws curiosity led me to investigate the matter, and I found that the subject of extraordinary tides was a matter of much simplicity ; that the chief factors reside in the moon with its varying distances and declinations; the next in the sun and the seasons; the next in the winds and atmosphere ; and the next, perhaps, in the action of the planets, as Venus and Jupiter, the former of which we know affects the orbit of the earth, and both have probably some power in producing the atmospheric disturbances in the sun.

With these factors I predicted a year in advance the extraordinary tide of November, 1875, which had escaped Capt. Saxby's notice. I was also able to say that there are two unusually high tides revolving through the year, exactly six-and-ahalf synodic months apart, each forty-eight days after the same tide of the previous year; that these with the preceding and succeeding tides are chiefly those which may with bad weather develop into extraordinary ones ; and that the next great onea very giant among tides-will be on March 20,1878 .

If Capt. Saxby has some knowledge on the subject which others have not, how is it he did not predict the unusually high tide of October 26 last, which happened when the moon was neither full nor new, nor in perigee? Why it happened is somewhat of a mystery; the only explanation I can suggest is, that the moon had her highest northern declination on that day, and that a barometric depression passed over the North Sea the previous day, both which would tend to heighten the tide.

November 12 B. G. JENKINS

\section{The Towering of Wounded Birds}

LAST season I fired at a song thrush at a distance of fifty yards, but the bird continued its course, as if uninjured, for upwards of 200 yards, when it suddenly "towered" in the air, and as suddenly fell to the ground. Upon examination the bird was found to have been shot through the lungs alone, and had bled internally, the throat being full of clotted blood. The head was totally free from any injury. I have known similar instances occur in the pigeon, swallow, and starling. In all these cases the head remained uninjured, and death occurred through internal hremorrhage. In the case of the starling one pellet entered the spine; the bird continued its course for a few yards, towered, and suddenly fell to the ground dead.

Should you consider these instances bearing on the matter of sufficient importance for an insertion in NATURE they may prove acceptable to those who are interested in the subject.

Heeley, near Sheffield

Charles Dixon

\section{Cruelty to Animals' Act and Physiological Teaching}

I AM desirous of knowing through your many readers if, amongst physiologists, the belief is anything like general, that showing under the microscope the circulation of the blood in a web of a frog's foot is a contravention of " The Cruelty to Animals' Act, 1876 ."

Dr. M. Foster, in his "Primer of Physiology" (Macmillan and Co., 1877 ), advises the reader to "go and look at it at once; you will never know any physiology till you do ;" and some naturalists here say if no incision is made, the animal being merely tied down, the exhibition of the phenomenon is quite legitimate, while, on the other hand, Prof. Huxley, in his paper before the Domestic Economy Congress (reported in NATURE, vol. xvi. p. 234) states it as his opinion that a teacher is "open to the penalty of fine and imprisonment if he uses" a frog "for the purpose of exhibiting one of the most beautiful and instructive of physiological spectacles."

It was this, the expressed opinion of so distinguished an authority as Prof. Huxley, which caused me first to doubt the teacher's right to exhibit the experiment, and it is because of the differences of opinion I have mentioned that I seek to know through your columns, if a teacher is or is not at-liberty to illustrate the blood circulation by this harmless experiment.

High School, Dundee, November 12

FRANK W. YOUNG

\section{Smell and"Hearing in Moths}

Numbers of moths, of many different species, are attracted into my room on summer evenings by the light; and they are fond of resting on the lamp shade. One night I was using some very strong ammonia solution--and by way of driving them off I held a 3-ounce bottle of it with the open mouth almost close to them. To my surprise they seemed quite unconscious of it as a smell; they would bear it unmoved for a minute, or sometimes for two or three minutes, and they then merely walked an inch or two further away from it. I have since tried the experiment repeatedly, and with several different s ecies; but none of them seem to detect the presence of ammonia except as a man might detect the presence of carbonic acid or of nitrogen in excess, that is, by their effects on his system generally.

The common black and white "magpie moth," it is well known, often feigns death when captured. I caught two, one after the other; both pretended "to be dead, and I laid them gently on the table a few inches apart. They had remained motionless for ten minutes, when I took up a wine glass by the stem, and gave it one sharp stroke with a pencil, about six inches away from them. Both moths flew off at the instant the sound was heard. I repeated this many times with the same resultboth with these and with other individuals of the sume species; and $I$ also found that merely holding the glass near them and waving the pencil about noiselessly, did not arouse them.

Loughton

J. C.

\section{Bees Killed by Tritoma}

IN a friend's garden here where there are quantities of Tr:tomas or "red-hot-pokers," hundreds of bees have been this year destroyed by them. The honey produced by the flower is very abundant, and the bees enter the tube of the corolla to get at it; but the tube, which is only just large enough at the mouth, tapers gradually, and so the bee gets wedged in and cannot extricate itself. I saw numbers so caught, some in the fresh flower, while others remained in the completely withered and decaying blossoms. Perhaps it may be due to the fine warm days we have had this autumn, inducing the bees to work too late after our native honey-producing flowers have been destroyed by the wet and frosts; or is it a regular thing which happens every year? If so bee-keepers should discourage the Tritoma, or set to work to select varieties with flowers large enough not to kill their bees.

Dorking, November 3

\section{Lecture Experiment}

THE experiment described below illustrates in a very striking manner the particular instance of the "conservation of energy" exhibited by the equilibrium of liquids of unequal densities, in communicating vessels.

The apparatus consists of a two-necked bottle, having in one neck a very strong glass tube half a metre, or more, in length, and terminating above in a funnel of $200 \mathrm{c}$.c. capacity, while its lower end nearly reaches the bottom of the bottle ; in the other neck is a piece of glass tube, drawn to a jet, and passing only a short distance into the bottle. As the pressure inside the appa. 